\title{
PEDAGOGÍA EN CONSTITUCIÓN POLÍTICA Y DEMOCRACIA PARA LA TRANSFORMACIÓN DE LA SOCIEDAD
}

\section{PEDAGOGY IN CONSTITUTION AND DEMOCRACY FOR THE TRANSFORMATION OF THE SOCIETY}

\author{
MSc.Mary Ramona Bohorquez Casadiego ${ }^{\mathrm{a}}$, MSc. Lina Fernanda Romero ${ }^{\mathrm{b}}$
}

${ }^{a}$ Universidad Francisco de Paula Santander Ocaña, Grupo de Investigación GIFEAH, Vía Acolsure Sede el Algodonal, Ocaña - Norte de Santander, Colombia, mrbohorquezc@ufpso.edu.co

${ }^{\mathrm{b}}$ Universidad Francisco de Paula Santander Ocaña, Grupo de Investigación GIFEAH, Vía Acolsure Sede el Algodonal, Ocaña - Norte de Santander, Colombia, linaromeroa@ufpso.edu.co

\begin{abstract}
Resumen: Para abordar la formación de los estudiantes de la educación media en las Instituciones Educativas, ubicadas en Ocaña Norte de Santander; se requiere del diseño de un modelo de estrategias pedagógicas que le permitan a los jóvenes, la apropiación de la Constitución Política y Democracia, no solo como un proceso de enseñanza-aprendizaje en el que se recibe el conocimiento, sino que se propenda por la comprensión y aprehensión de cómo debe ser su actuación como ciudadano, frente a la responsabilidad ante el cumplimiento de los deberes para luego poder reclamar y exigir sus derechos como colombianos. Desde el Ministerio de Educación Nacional, a través de la Ley 115 en su artículo 78, se estipulan unos lineamientos del área de Ciencias Sociales para la Educación básica y media, donde se incluyen los contenidos concernientes a Constitución Política y Democracia, considerados de carácter obligatorio; sin embargo, puede notarse la ausencia de pautas para abordar, dichos contenidos. Es aquí donde radican las falencias, si se tiene en cuenta que cada docente posee la facultad y la libertad de abordar la cátedra a su entera voluntad y conveniencia. Por ello: algunos de los temas, corren el riesgo de no ser abordados por considerarlos menos importantes, o que se aborden únicamente, los que tienen relación con los procesos electorales escolares.
\end{abstract}

Palabras clave: Aprendizaje significativo, Ciudadanos críticos, Constitución política y democracia, Estrategias pedagógicas, Formación docente. 
Abstract: For the training of students in secondary education in educational institutions in Ocaña, it is necessary to have a model and a pedagogical strategies that will enable young people, the appropriation of the Political Constitution and democracy, not only as a process teaching and learning in which knowledge is received, but there is understanding and apprehension of what should be their role as citizen, facing the responsibility to fulfill the duties and then to claim and demand their rights as Colombians. The Ministry of National Education, through Law 115 Article 78, some guidelines of Social Sciences for primary and secondary education, where the contents concerning Constitution and Democracy include stipulated considered mandatory; however, there are no guidelines on how to approach these contents. This is where lie the failures, because each teacher has the freedom to address the chair, but sometimes do not know the right way, and therefore, some of the issues are considered less important, addressing only those that they are related with school elections.

Keywords: Meaningful learning, Critical citizens, Political constitution and democracy, Teaching strategies, Teacher training.

\section{INTRODUCCIÓN}

No puede considerarse un secreto, la situación por la que atraviesa Colombia e igualmente sus departamentos y municipios, en donde no sólo se sufre por la falta de atención en salud, o porque la niñez de los sectores menos favorecidos mueren por desnutrición; o porque la inseguridad en las calles no solo es de las grandes capitales, sino también de los pequeños poblados, aunque muchos no lo perciban así. El propósito de este artículo de investigación, no radica fundamentalmente en este tema pero lo que se pretende, es relacionar lo que sucede a nivel general con los resultados de una administración o de un gobierno con grandes falencias, pudiéndose responsabilizar de esta situación, a los políticos de este país. Sin embargo vale la pena hacer un alto en el camino, y plantear los siguientes cuestionamientos: ¿Quiénes están en el poder?, ¿Cuál fue su formación en aspectos políticos y democráticos? ¿Cómo llegaron a él? La respuesta no parece tener mayor dificultad en decir que la responsabilidad es de los ciudadanos por no saber elegir y por ello se recurre en muchas ocasiones a la famosa frase: "Cada pueblo tiene el gobierno que se merece".

A pesar de ello, y de la responsabilidad que se pueda tener, lo que se pretende en este proceso, es entender cómo se deben formar a las futuras generaciones, en lo concerniente a Constitución Política y Democracia. Es decir que este tema se convierta en una opción obligada para proyectar la detención de la politiquería y el desarrollo de procesos de elección fraudulentos, en donde se elige por un interés individual mas no por la preocupación en la búsqueda de un rumbo diferente para un país en donde los problemas, parecen ir cada vez más en aumento. 
Las Instituciones de Educación Media en Ocaña, y a nivel nacional, deben estar comprometidas en la formación de ciudadanos críticos, comprometidos con el cumplimiento del quehacer de las instituciones democráticas y de las directrices expresadas en la Constitución Política de Colombia. Se puede decir así que esta es la única forma en que se puedan cambiar las percepciones y lograr transformar el presente de esta nación.

Es aquí en donde el Ministerio de Educación parece haber olvidado una de sus responsabilidades, pues sólo se preocupó por definir las áreas y los lineamientos generales de las ciencias sociales que se deben abordar en la educación básica y media, sin establecer puntualmente las temáticas, los procesos y los procedimientos de formación para adquirir las competencias que debe tener un bachiller para el caso de Constitución Política y Democracia; así como lo expresa el Dr. Francisco José Lloreda Mera:

La Constitución Política de Colombia y su reglamentación abre grandes espacios y posibilidades para que las y los colombianos construyamos un nuevo país y una nueva sociedad; una nación donde los distintos actores que la conformamos logremos desarrollarnos en un sentido más humano e integral. Es así como la educación y las Ciencias Sociales, están llamadas a colaborar de manera urgente y primordial con esa transformación que anhelamos, propiciando ambientes de reflexión, análisis crítico, ajustes progresivos y propositivos que ayuden, a las y los jóvenes, a afrontar las problemáticas de hoy y del futuro.

Frente a este escenario, los docentes que tiene la obligación de impartir la cátedra del área de ciencias sociales en la educación media en el municipio de Ocaña, no tienen más opción que buscar y hacer un análisis propio de los temas que se trabajarán respecto a Constitución Política y Democracia, considerándose este como un problema menor, frente a la preocupación que surge en los profesores cuando van a trasmitir el conocimiento y no tener claridad sobre la estrategia pedagógica, propicia para el tema.

\section{METODOLOGÍA}

La investigación que sirvió de base para la elaboración de éste artículo, se orientó bajo un enfoque cualitativo y por consiguiente se optó por una postura hermenéuticointerpretativa. Con base en esta postura, no se buscaron verdades absolutas, sino la construcción de un compendio, producto del análisis de los aspectos que hicieron relación a la realidad investigada en busca de ser compartidos para el mejoramiento de la situación analizada. A partir de este acercamiento metodológico en la ejecución del presente estudio, las actividades que lo materializaron, se enuncian a continuación: 
Como preámbulo al trabajo de campo, se hizo un cuidadoso y detallado análisis documental de los contenidos programáticos relacionados con el Componente Constitución Política y democracia, en cinco de los 13 colegios ubicados en Ocaña. El trabajo de campo, se orientó, en la realización de entrevistas en profundidad a cinco docentes titulares de la asignatura Ciencias Sociales y cinco, a estudiantes de 10 y 11 .

El desarrollo de la entrevista, estuvo precedida por la elaboración de un formato, en el cual se plasmaron preguntas relacionadas con los siguientes aspectos: Estrategias planteadas para impulsar el programa de Constitución política y democracia e Iniciativas a desarrollar para el conocimiento del mismo; enfoque pedagógico utilizado en el proceso enseñanza aprendizaje de la cátedra; Tipo de formación que requieren los docentes para adelantar ésta y conocimiento de la forma como se está llevando a cabo, dicho programa.

\section{RESULTADOS}

El Análisis e interpretación de los datos recopilados, permitieron llegar a las siguientes apreciaciones:

- Inexistencia de una estrategia clara y específicamente diseñada para la formación en el tema que nos ocupa; aspecto fundamentado en la barrera existente, entre docente-estudiante frente al proceso de enseñanza aprendizaje; al quedar definido por el sujeto activo, la estructura a seguir, sin que el sujeto pasivo, pueda tener participación en el mismo. De esta forma, se percibe el uso de la comunicación unidireccional de conocimientos del profesor a los alumnos, dificultándose la garantía del equilibrio y la coherencia de este circuito. Así mismo, el proceso de aprendizaje se produce a través de la realización de una actividad propuesta por parte del profesor, sin la participación de los estudiantes; quedando demostrado que el alumno no percibe unidad y coherencia, sino actividades diversas e inconexas, sin un horizonte conceptual claro.

- Respecto al conocimiento del programa, se pudo notar que la temática de constitución política y democracia, carece de una estructura programática definida; quedando a juicio del docente, la inclusión del proceso de elección del consejo estudiantil, dentro del contenido de las ciencias sociales; siendo este aparte, el único componente abordado en relación con el tema central.

- El enfoque pedagógico que fundamenta el proceso enseñanza- aprendizaje en este proceso de formación, es el conductista, quedando el estudiante sometido a las prácticas definidas por el docente, donde de hecho se visualiza la castración de los conceptos que denotan su forma de pensar. No cabe discusión de lo anteriormente descrito, al ser producto de una escuela 
verticalmente autoritaria, que no facilita ambientes y situaciones democráticas, donde no se permite el disenso, ni la discusión de las reglas y manuales para la convivencia, ¿Cómo fomentar actitudes democráticas, de sana discusión, de tolerancia, etc., entre los estudiantes? Y sí que menos, pensar en una educación integral del ser humano.

- Se considera que el docente, debe ser formado para abordar la situación presente y transformar al estudiante de sujeto pasivo en sujeto activo. Por lo anterior, se requiere que la formación del mismo, recaiga en el Aprendizaje Significativo por ser un proceso constructivo, activo, contextualizado, social y reflexivo.

Aprender con sentido, aprendizaje significativo, a partir de lo que se conoce y con tareas reales. En este enfoque el protagonista del aprendizaje es el propio estudiante. El papel del profesor es guiar, acompañar, evaluar el proceso, apoyar al educando, mientras sea necesario... guiar al estudiante en el proceso de aprender a aprender, ayudarlo en la creación de unas estructuras cognitivas o esquemas mentales que le permitan manejar la información disponible, filtrarla, codificarla, categorizarla, evaluarla, comprenderla y utilizarla pertinentemente. El educador va cediendo terreno, al otro que va logrando autonomía e independencia, en su aprendizaje. (FERNANDEZ MARCH, 2006)

\section{CONCLUSIONES}

Buscando generar un cambio en la participación política de los ciudadanos de hoy, se debe comenzar a trabajar desde el proceso de formación de los jóvenes para que se conviertan en los futuros ciudadanos, quienes tiene la responsabilidad de ser proactivos frente a las situaciones que se presentan a nivel de una Democracia, como en la que está inmerso el país. Para ello se considera imprescindible la formación de los docentes, en el modelo de aprendizaje significativo.

De igual manera, se debe plantear la construcción de un módulo sobre los lineamientos para el desarrollo de la Cátedra de Constitución Política y Democracia.

\section{FINANCIACIÓN}

El desarrollo del proyecto de investigación que arrojó como resultado este artículo es "Análisis del proceso de formación en Constitución Política y Democracia en la educación media en Ocaña”. Afortunadamente este trabajo fue respaldado por el Grupo de Investigación de la Facultad de Educación, Artes y Humanidades (GIFEAH), y con el apoyo financiero de la Universidad Francisco de Paula Santander. 


\section{BIBLIOGRAFÍA}

Decreto 1860 MEN (Bogotá, 1994 Agosto 3), reglamentario de la Ley $115 \mathrm{del}$ 8 de febrero de 1994, de

FRANCISCO CAJIAO. (Bogotá, 1989.) Pedagogía de las Ciencias Sociales. Intereditores.

FERNADEZ MARCH. Amparo. (2006). Metodologías activas para la formación del pensamiento. Revista Educación Siglo XXI (24), 35-36.

Ley General de Educación", (Bogotá, 1994).

"Lineamientos curriculares (Bogotá, 1998).Constitución Política y Democracia y Educación Ética y Valores Humanos,

MICHAEL IBBONS, y otros. (Barcelona, 199) La nueva producción del conocimiento. La dinámica de la ciencia y la investigación en las sociedades contemporáneas. Ediciones Pomares Corredor,

M. MARTÍNEZ, (Bogotá, 2002). La Investigación Cualitativa Etnográfica en Educación. Circulo de lectura alternativa Ltda.

NORBERTO BOBBIO. (Madrid, 1994) El Futuro de la Democracia. Ed. Fondo de Cultura Económica,

RAQUEL PULGARÍN, y otros. (Medellín, julio de 2001) Necesidades, sentido histórico y tareas en la formación en Ciencias Sociales en el contexto escolar antioqueño. Mesa de trabajo de Ciencias Sociales del departamento de Antioquia. Documento mimeografiado.

RESTREPO,
GABRIEL;
SARMIENTO, JOSUÉ Y RAMOS
JAVIER，(Bogotá，2000). Orientaciones curriculares para Ciencias Sociales en la educación media. Documento mimeografiado. 